\title{
Determination of normal values for navicular drop during walking: a new model correcting for foot length and gender Rasmus G Nielsen*1, Michael S Rathleff ${ }^{*}$, Ole H Simonsen ${ }^{1}$ and Henning Langberg ${ }^{2}$
}

\author{
Address: ${ }^{1}$ Orthopaedic Division, North Denmark Region, Aalborg Hospital, part of Aarhus University Hospital, Denmark and ${ }^{2}$ Institute of Sports \\ Medicine, Department of Rheumatology, Bispebjerg Hospital, Copenhagen University Hospital, Copenhagen, Denmark \\ Email: Rasmus G Nielsen* - ragn@rn.dk; Michael S Rathleff - misr@rn.dk; Ole H Simonsen - ohs@rn.dk; \\ Henning Langberg - henninglangberg@gmail.com \\ * Corresponding author
}

Published: 7 May 2009

Journal of Foot and Ankle Research 2009, 2:12 doi:10.1186/1757-1 146-2-12

This article is available from: http://www.jfootankleres.com/content/2/1/12

(C) 2009 Nielsen et al; licensee BioMed Central Ltd.

This is an Open Access article distributed under the terms of the Creative Commons Attribution License (http://creativecommons.org/licenses/by/2.0), which permits unrestricted use, distribution, and reproduction in any medium, provided the original work is properly cited.
Received: 26 January 2009

Accepted: 7 May 2009

\begin{abstract}
Background: The navicular drop test is a measure to evaluate the function of the medial longitudinal arch, which is important for examination of patients with overuse injuries. Conflicting results have been found with regard to differences in navicular drop between healthy and injured participants. Normal values have not yet been established as foot length, age, gender, and Body Mass Index (BMI) may influence the navicular drop. The purpose of the study was to investigate the influence of foot length, age, gender, and BMI on the navicular drop during walking.
\end{abstract}

Methods: Navicular drop was measured with a novel technique (Video Sequence Analysis, VSA) using 2D video. Flat reflective markers were placed on the medial side of the calcaneus, the navicular tuberosity, and the head of the first metatarsal bone. The navicular drop was calculated as the perpendicular distance between the marker on the navicular tuberosity and the line between the markers on calcaneus and first metatarsal head. The distance between the floor and the line in standing position between the markers on calcaneus and first metatarsal were added afterwards.

Results: 280 randomly selected participants without any foot problems were analysed during treadmill walking (I44 men, I 36 women). Foot length had a significant influence on the navicular drop in both men $(p<0.00 I)$ and women $(p=0.015)$, whereas no significant effect was found of age $(p=0.27)$ or BMI $(p=0.88)$. Per $10 \mathrm{~mm}$ increase in foot length, the navicular drop increased by $0.40 \mathrm{~mm}$ for males and $0.31 \mathrm{~mm}$ for females. Linear models were created to calculate the navicular drop relative to foot length.

Conclusion: The study demonstrated that the dynamic navicular drop is influenced by foot length and gender. Lack of adjustment for these factors may explain, at least to some extent, the disagreement between previous studies on navicular drop. Future studies should account for differences in these parameters. 


\section{Background}

The medial longitudinal arch (MLA) plays an important role in shock absorbance and energy transfer during walking $[1,2]$. Arch function depends on the shape of the foot [3], bony structure [4], ligamentous stability $[5,6]$, and muscular fatigue [7] while factors like race $[8,9]$, footwear $[10,11]$, age, and gender [12] are found to influence the formation of MLA.

High-arched and low-arched foot types seem to be a risk factor for overuse injuries in sport activities. Dahle [13] found knee pain more common in football players with pronated or supinated foot types, compared with neutral foot type. Williams [14] found high-arched runners to have more ankle, bony, and lateral sided injuries, while low-arched runners had more knee, medial sided, and soft tissue injuries. Although there are trends in the literature implicating foot position, statically or dynamically, as a risk factor for exercise related injuries, Wen [15] found the literature inconclusive in a recent review. In his opinion one drawback of several studies is a failure to control for confounding variables.

Brody [16] introduced the static navicular drop test as a measure to evaluate MLA. In previous studies, mean values among healthy adults range from 3.6 to $8.1 \mathrm{~mm}$ in the original version of the test [17-21] and from 7.3 to 9.0 $\mathrm{mm}$ in modified versions [22,23]. Brody [16], Beckett [24], and Mueller [19] suggested 15, 13, and $10 \mathrm{~mm}$, respectively, as the upper limit for a normal navicular drop [25]. It has shown moderate to good reliability $[18,19,26]$, also when compared with x-ray examination [27].

Static navicular drop has been a relatively poor predictor of the navicular drop (ND) during walking [28]. A dynamic navicular drop test was introduced by Cornwall and McPoil [29] using a 6D electromagnetic motion analysis system. Among 106 healthy participants ND was found to be $5.9 \mathrm{~mm}(S \mathrm{SD} \pm 2.8)$.

The relation between foot function and various pathologies has been examined in a few studies. Among 50 participants with ACL rupture, Beckett [24] found increased static ND $(13 \pm 4.4 \mathrm{~mm}$, mean $\pm \mathrm{SD})$ compared with noninjured $(6.9 \pm 3.2 \mathrm{~mm})$, and Reinking [30] observed a significantly increased incidence of exercise related leg pain among female athletes with a static navicular drop greater than $10 \mathrm{~mm}$.

In his review Menz [25] suggested that limits of abnormal drop should be interpreted with caution, as he speculated that the ND could be influenced by foot length. This was supported by Weiner-Ogilvie and Rome [31], who proposed that an "acceptable range of normative values for clinical measurements of foot position" is needed. To our knowledge, no studies have investigated the influence of foot length, gender, age, and body mass index (BMI) on the ND during walking, which thus became the purpose of this study.

\section{Methods \\ Participants}

The study was approved by the local ethics committee ( $\mathrm{N}$ 20070049). Informed written consent was obtained from the participants prior to the experiments. From the Danish Central Personal Register adult citizens from Aalborg Municipality were randomly selected. 320 agreed to participate. 40 participants were excluded because of overweight, age, injuries, data loss and a disability to walk on treadmill. Finally 280 healthy volunteers aged 18-68 years were included. Inclusion criteria were no lower extremity deformities or major trauma, and no pain in the lower extremity during the last three months.

\section{Procedures}

The foot length was measured with a ruler from the most posterior aspect of calcaneus to the tip of the longest toe. The foot length ranged from $21-31 \mathrm{~cm}$ (table 1). Custom made flat markers with a diameter of $13.5 \mathrm{~mm}$ made from reflective $3 \mathrm{M}$ scotch tape were used. The markers were placed while participants were seated with the subtalar joint in a neutral position. Neutral position of the subtalar joint was defined as the position where talus could be palpated equally on the medial and lateral side of the foot [18]. An experienced clinician placed the markers with adhesive tape on (i) the navicular tuberosity, (ii) medial aspect of calcaneus $2 \mathrm{~cm}$ above the floor and $4 \mathrm{~cm}$ from the most posterior aspect of the calcaneus, and (iii) medial aspect of first metatarsal head $2 \mathrm{~cm}$ above the floor (figure 1).

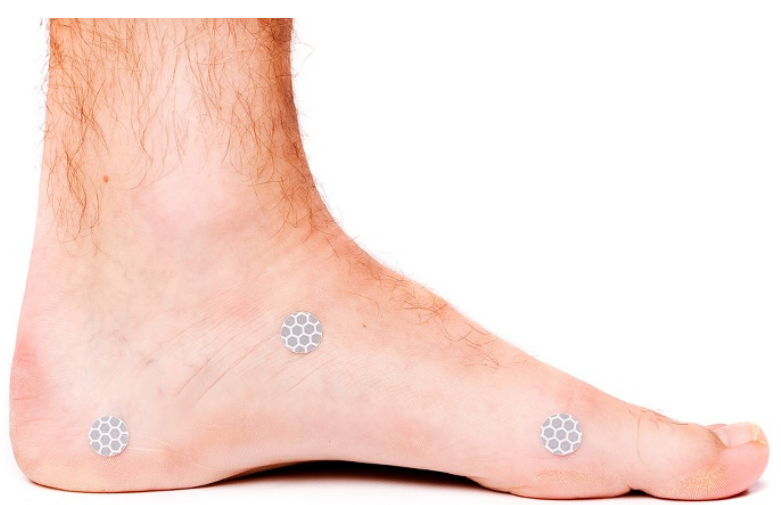

Figure I

Reflective marker positions used to calculate navicular drop (ND). 
Table I: Demographic characteristics of the participants tested.

\begin{tabular}{lcccc}
\hline Parameters & $\begin{array}{c}\text { All } \\
(\mathrm{n}=280)\end{array}$ & & $\begin{array}{c}\text { Women } \\
(\mathrm{n}=136)\end{array}$ & $\begin{array}{c}\text { Men } \\
(\mathrm{n}=144)\end{array}$ \\
\hline Mean (SD) & Range & Mean (SD) & Mean (SD) \\
\hline Age (years) & $43(31-54)$ & $18-68$ & $43(34-60)$ & $42,5(30-54)$ \\
\hline Height $(\mathrm{m})$ & $1.74( \pm 0.08)$ & $1.55-1.93$ & $1.68( \pm 0.06)$ & $1.79( \pm 0.06)$ \\
\hline Weight $(\mathrm{kg})$ & $73.4( \pm 12.1)$ & $43-107$ & $66.5( \pm 9.3)$ & $80.0( \pm 10.7)$ \\
\hline BMI $\left(\mathrm{kg} / \mathrm{m}^{2}\right)$ & $24.2( \pm 3.1)$ & $17.6-30.5$ & $23.5( \pm 3.1)$ & $24.8(2.9)$ \\
\hline Foot length $(\mathrm{cm})$ & $25.3( \pm 1.8)$ & $21-31$ & $24.1( \pm 1.3)$ & $26.5( \pm 1.3)$ \\
\hline
\end{tabular}

* age presented as median and interquartil range.

The participants were instructed to walk bare-footed on a treadmill at self-selected speed. After an accommodation period of six minutes [32], recordings were carried out for $20 \mathrm{sec}$.

A 2D motion capture system (VSA) was used to measure ND during walking [33]. It consists of a digital video camera (Basler Scout; Basler AG, Ahrensburg, Germany) with a $12 \mathrm{~mm}$ lens sampling at $86 \mathrm{~Hz}$. The camera was mounted perpendicular to the sagittal plane at the level of the foot on the treadmill. ND was defined as the maximal vertical movement of the navicular bone from heel strike to the minimal height between the navicular tuberosity and the floor. It was calculated as the perpendicular distance between the marker on the navicular tuberosity and the line between the markers on calcaneus and first metatarsal head. The distance between the floor and the line in standing position between the markers on calcaneus and first metatarsal were added afterwards. ND was calculated as the mean of 20 consecutive steps.

The system was found highly reliable in a test/retest pilot study with ICC values for ND at 0.95 (within day) and 0.94 (between days).

\section{Statistical analysis}

All data except age were parametric and therefore the Pearson product moment correlation was used. The Spear- man's rank correlation was used in the analysis of age. Correlations and stepwise multiple regression techniques were applied to test for relationships between parameters. SPSS (SPSS Inc, Chicago, Illinois, USA) version 15.0 was used.

\section{Results}

Dynamic ND ranged from 1.7 - $13.4 \mathrm{~mm}$. (Table 2). 95\% of the population had an ND less than $8.7 \mathrm{~mm}$ and greater than $1.7 \mathrm{~mm}$. Approximately the same mean ND was observed among women and men $(5.2$ and $5.3 \mathrm{~mm}$. respectively). BMI and age were found not to influence ND. (Table 3) Only foot length had an isolated significant effect on ND $(\mathrm{p}<0.01)$.

By linear regression models it is shown that gender induced a modification on the effect of foot length on dynamic ND. (Table 4). The table should be read by looking at how the foot length affects ND. The B-value represents the slope of the regression, so in this case it means that the regression predicted an increase in ND in male participants of $0.40 \mathrm{~mm}(95 \%$ CI $0.19-0.62 \mathrm{~mm}$.) every time the foot length was increased with one $\mathrm{cm}$. For women the increase in ND per $\mathrm{cm}$ increase in foot length was $0.31 \mathrm{~mm}(95 \% \mathrm{CI} 0.10-0.53 \mathrm{~mm}$.).

The Pearson product moment correlation was 0.295 (p < 0.001 ) between foot length and ND among males and

Table 2: Mean navicular drop (ND) in men and women.

\begin{tabular}{lcccc}
\hline Parameters & $\begin{array}{c}\text { All } \\
(\mathrm{n}=280)\end{array}$ & $\begin{array}{c}\text { Women } \\
(\mathrm{n}=136)\end{array}$ & $\begin{array}{c}\text { Men } \\
(\mathrm{n}=144)\end{array}$ \\
\hline & Mean \pm SD & Range & Mean \pm SD & Mean \pm SD \\
\hline Navicular drop $(\mathrm{mm})$ & $5.3( \pm 1.7)$ & $1.3-13.4$ & $5.2( \pm 1.6)$ & $5.3( \pm 1.8)$ \\
\hline
\end{tabular}


Table 3: Correlations (Pearson's $r$ and $p$-value) between navicular drop (ND) and body mass index (BMI), age and foot length.

\begin{tabular}{lcc}
\hline Correlations & Women & Men \\
\hline BMI & $-0.03(0.77)$ & $0.002(0.98)$ \\
\hline Foot length/cm & $0.21(0.02)$ & $0.265(0.001)$ \\
\hline Agelyears & $-0.052(0.55)$ & $-0.12(0.16)$ \\
\hline
\end{tabular}

$0.241(\mathrm{p}=0.005)$ among females. A scatter plot was created showing the variation of ND among male (figure 2) and female participants (figure 3).

\section{Discussion}

We investigated the influence of foot length, age, gender, and BMI on the dynamic ND during walking. A positive correlation between foot length and dynamic ND was observed among these healthy participants without foot problems. $97.5 \%$ of this population had a dynamic ND of less than $8.5 \mathrm{~mm}$. Thus this value could be considered as the cut-off value between normal participants and participants with abnormal ND which would correspond nicely to the $10 \mathrm{~mm}$ borderline suggested by Mueller [19] for the static ND. However, as the dynamic ND is influenced by foot length and the gender, the normal value for individual dynamic ND must be given relative to foot length and the gender (Figure 2 and 3 ). As foot length increases from $22-28 \mathrm{~cm}$, the upper value (95\% confident limit) of abnormal ND increases from $7.25 \mathrm{~mm}$ to $9.50 \mathrm{~mm}$ for males and from $7.8 \mathrm{~mm}$ to $10 \mathrm{~mm}$ for females.

Male participants had a mean drop of $3.9 \mathrm{~mm}$ with a foot length of $23 \mathrm{~cm}$, while the mean drop was $6.9 \mathrm{~mm}$ with foot length of $30.5 \mathrm{~cm}$ giving a $3 \mathrm{~mm}$ difference between a small and a large male foot. Bandholm et al. [34] reported a significant difference in static ND of $2.8 \mathrm{~mm}$ between injured and healthy participants. However the static ND was not adjusted for foot length which, hypothetically, could explain the difference.
The mean ND $(5.3 \mathrm{~mm})$ found in present study also agrees with the mean dynamic ND $(5.9 \mathrm{~mm})$ found by Cornwall and McPoil [29] using an electromagnetic motion analysis system. In the present VSA system, dynamic ND was calculated as the navicular drop from heel strike to minimal navicular height, while the electromagnetic method used the difference from foot flat to heel off to calculate the "maximum vertical depression". This methodological difference may explain the $0.6 \mathrm{~mm}$ difference between the systems.

Measurement of the static ND might be the most appropriate technique for the clinical assessment of foot pronation [25]. Therefore simple and reliable methods to measure dynamic ND are highly warranted. Hitherto the reliability for one- and 2-D video systems has been too low for clinical and scientific purposes, and 3-D video systems are too expensive and space consuming for most clinics. The present knowledge about the relation between foot dysfunction and overuse injuries is primarily based upon 3-D video analysis. By the introduction of VSA we have demonstrated that a $2-\mathrm{D}$ video system can be at least as reliable as the multiple camera systems in the traditional 3-D analysis. The 0.94 ICC for the present VSA is even higher than the 0.86 ICC found for a 3-D system with the same skin marker positioning [34]. The use of 2$\mathrm{D}$ measurements in the sagittal plane corresponds well with three-dimensional measurement results in more advanced systems [35], which strengthen the method used in this study. 2-D video analysis requires one room and can be performed within a few minutes. Therefore the VSA is highly suitable for routine clinical examination and for studies requiring a large number of participants.

We found that age and BMI did not significantly influence the ND. However, we did not include participants with BMI larger than 30.5 and participants older than 68 years. Therefore it is still unknown whether BMI larger than 30.5 will influence the ND. Lai et al [36] found significant differences in ankle kinematics during walking between the obese and the non-obese participants. Likewise it remains to be studied whether age older than 68 years will influence the ND.

Table 4: The influence of foot length on navicular drop (ND).

\begin{tabular}{lccccc}
\hline & $\begin{array}{c}\text { Women }(\mathrm{n}=136) \\
\text { Navicular drop }(\mathrm{mm})\end{array}$ & $P$ & $\begin{array}{c}\text { Men }(\mathrm{n}=144) \\
\text { Navicular drop (mm) }\end{array}$ \\
\hline B & $95 \% \mathrm{Cl}$ & $\mathrm{B}$ & $95 \% \mathrm{Cl}$ & $\mathrm{P}$ \\
\hline Foot length & -2.34 & $-7.55-2.87$ & 0.376 & -5.36 & $-11.11-0.39$ \\
\hline
\end{tabular}




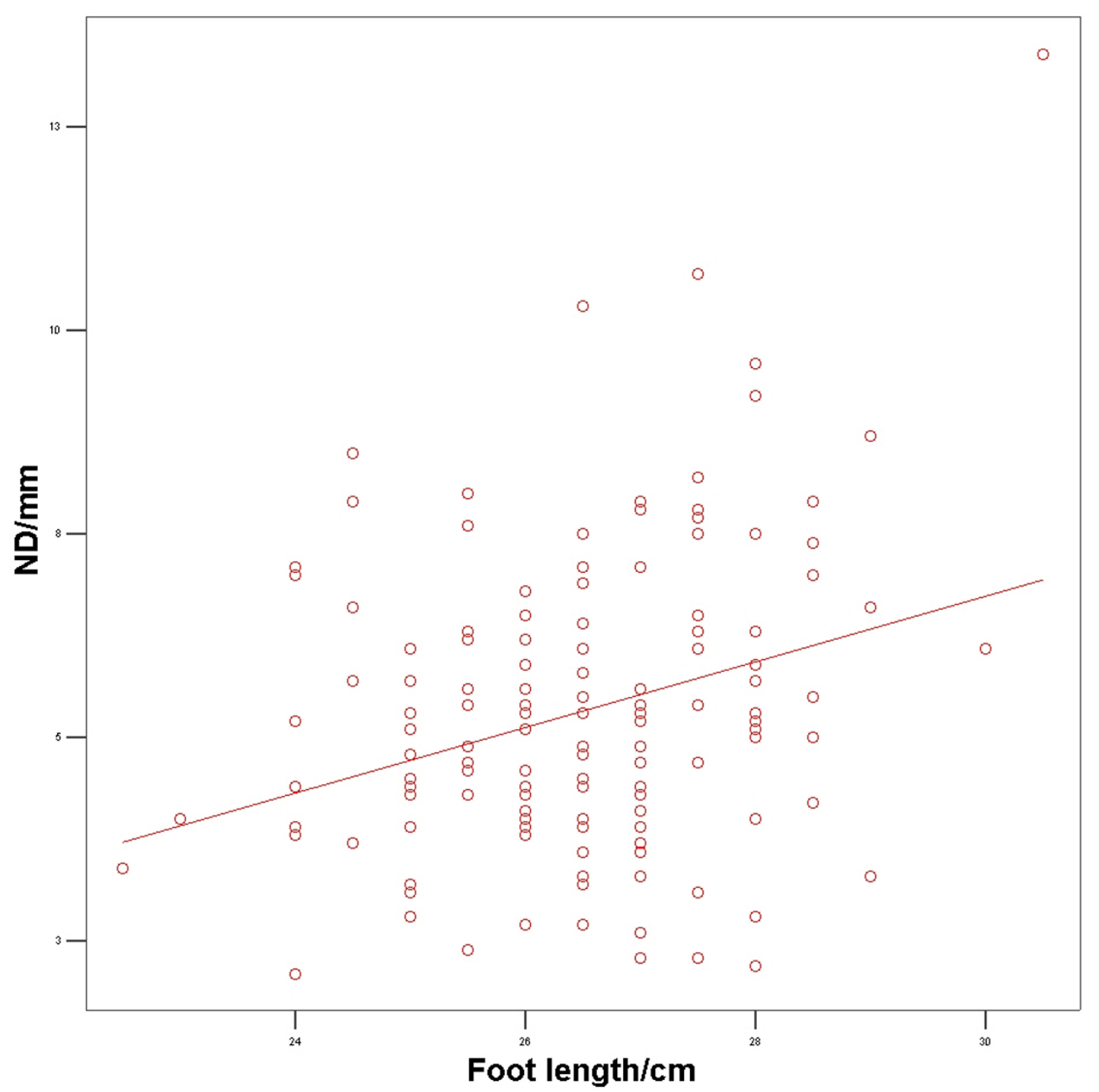

Figure 2

Scatterplot showing the variation of navicular drop among male participants.

\section{Conclusion}

The present study demonstrates that the dynamic navicular drop is influenced by foot length and gender. Male participants had an increase in drop of $0.40 \mathrm{~mm}$ every time the foot length is increased by $10 \mathrm{~mm}$. The female participants had an increase of $0.31 \mathrm{~mm}$ every time the foot length is increased by $10 \mathrm{~mm}$. Lack of adjustment for foot length and gender may cause invalid significant differences when comparing navicular drop between two groups. Future studies should adjust for foot length and gender when examining the navicular drop. For a valid comparison of participants in case-control studies we recommend matching people by foot length and gender.

\section{Competing interests}

The authors declare that they have no competing interests.

\section{Authors' contributions}

RGN designed the study, applied for approval by the local ethics committee (N-20070049), took part in data acquisition, and drafted the manuscript. MSR took part in data acquisition, made the statistical analysis and interpretation of data, and helped drafting the manuscript. OS and HL took part in revising the manuscript critically for important intellectual content. All authors read and approved the final manuscript. 


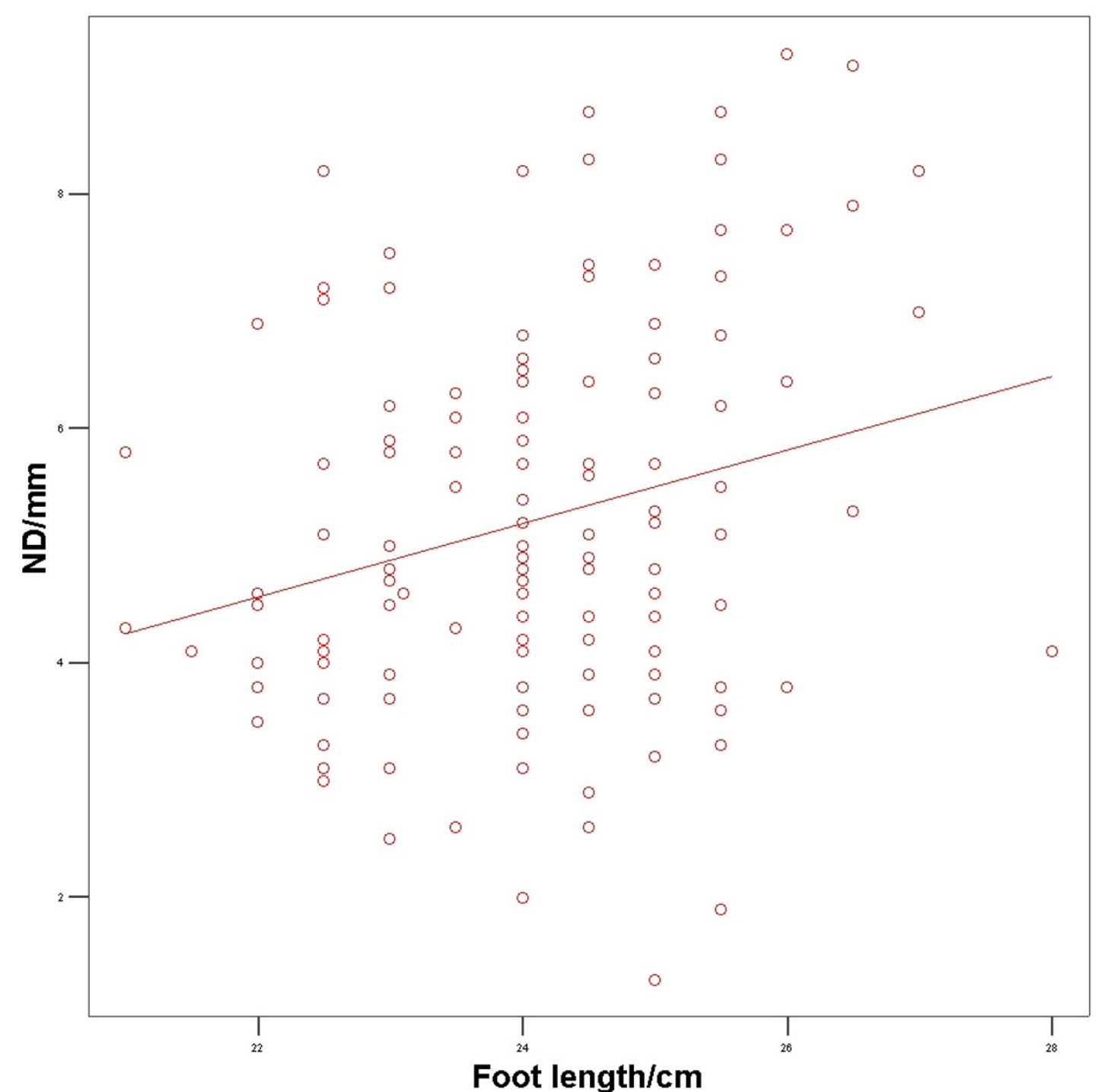

Figure 3

Scatterplot showing the variation of navicular drop among female participants.

\section{Acknowledgements}

Foot and Ankle Research Northern Denmark (FARND) is acknowledged for acquisition of funding, collection of data, and general supervision of the research group.

The study was financially supported by Den Faberske Fond Ryeslinge, Denmark, The Association of Danish Physiotherapists Research Fund, Denmark, and Center for Sundhedsteknologi, Aalborg University, Denmark.

\section{References}

I. Ker RF, Bennett MB, Bibby SR, Kester RC, Alexander RM: The spring in the arch of the human foot. Nature 1987, 325:147-9.

2. Ogon M, Aleksiev AR, Pope MH, Wimmer C, Saltzman CL: Does arch height affect impact loading at the lower back level in running? Foot Ankle Int 1999, 20:263-6.
3. Nack JD, Phillips RD: Shock absorption. Clin Podiatr Med Surg 1990, 7:391-7.

4. Franco AH: Pes cavus and pes planus. Analyses and treatment. Phys Ther 1987, 67:688-94.

5. Kitaoka HB, Luo ZP, An KN: Three-dimensional analysis of flatfoot deformity: cadaver study. Foot Ankle Int 1998, 19:447-5I.

6. Richie DH Jr: Biomechanics and clinical analysis of the adult acquired flatfoot. Clin Podiatr Med Surg 2007, 24:617-44.

7. Headlee DL, Leonard JL, Hart JM, Ingersoll CD, Hertel J: Fatigue of the plantar intrinsic foot muscles increases navicular drop. J Electromyogr Kinesiol 2008, 1 8:420-5.

8. Stewart SF: Human gait and the human foot: an ethnological study of flatfoot. I. Clin Orthop Relat Res 1970, 70: I I I-23.

9. Stewart SF: Human gait and the human foot: an ethnological study of flatfoot. II. Clin Orthop Relat Res 1970, 70: 124-32.

10. Rao UB, Joseph $B$ : The influence of footwear on the prevalence of flat foot. A survey of $\mathbf{2 3 0 0}$ children. J Bone Joint Surg Br 1992, 74:525-7. 
II. Sachithanandam V, Joseph B: The influence of footwear on the prevalence of flat foot. A survey of 1846 skeletally mature persons. J Bone Joint Surg Br 1995, 77:254-7.

12. Volpon JB: Footprint analysis during the growth period. J Pediatr Orthop 1994, 14:83-5.

13. Dahle LK, Mueller MJ, Delitto A, Diamond JE: Visual assessment of foot type and relationship of foot type to lower extremity injury. J Orthop Sports Phys Ther 1991, I 4:70-4.

14. Williams DS III, McClay IS, Hamill J: Arch structure and injury patterns in runners. Clin Biomech (Bristol, Avon) 200I, 16:341-7.

15. Wen DY: Risk factors for overuse injuries in runners. Curr Sports Med Rep 2007, 6:307-13.

16. Brody DM: Techniques in the evaluation and treatment of the injured runner. Orthop Clin North Am I 982, I 3:54I-58.

17. Bennett JE, Reinking MF, Pluemer B, Pentel A, Seaton M, Killian C: Factors contributing to the development of medial tibial stress syndrome in high school runners. J Orthop Sports Phys Ther 200I, 3 I:504-I0.

18. Sell KE, Verity TM, Worrell TW, Pease BJ, Wigglesworth J: Two measurement techniques for assessing subtalar joint position: a reliability study. J Orthop Sports Phys Ther 1994, 19:162-7.

19. Mueller MJ, Host JV, Norton BJ: Navicular drop as a composite measure of excessive pronation. I Am Podiatr Med Assoc 1993, 83:198-202.

20. Allen MK, Glasoe WM: Metrecom Measurement of Navicular Drop in Subjects with Anterior Cruciate Ligament Injury. J Athl Train 2000, 35:403-6.

21. Joyce CJ, Arnold BL, Gansneder BM: Differences between navicular drop measures. J Athl Train 1999, 34:S7I.

22. Moul JL: Differences in Selected Predictors of Anterior Cruciate Ligament Tears Between Male and Female NCAA Division I Collegiate Basketball Players. J Athl Train I998, 33: I I8-2I.

23. Picciano AM, Rowlands MS, Worrell T: Reliability of open and closed kinetic chain subtalar joint neutral positions and navicular drop test. J Orthop Sports Phys Ther 1993, I 8:553-8.

24. Beckett ME, Massie DL, Bowers KD, Stoll DA: Incidence of Hyperpronation in the ACL Injured Knee: A Clinical Perspective. J Athl Train 1992, 27:58-62.

25. Menz HB: Alternative techniques for the clinical assessment of foot pronation. J Am Podiatr Med Assoc 1998, 88: I 19-29.

26. Vinicombe A, Raspovic A, Menz HB: Reliability of navicular displacement measurement as a clinical indicator of foot posture. J Am Podiatr Med Assoc 200I, 91:262-8.

27. Hannigan-Downs K, Harter R, Smith G: Radiographic Validation and Reliability of Selected Clinical Measures of Pronation. J Athlet Train 2000, 35(supplement): I2-30.

28. Rathleff M, Nielsen R, Olesen C, Simonsen O, Moelgaard CM, Jensen $\mathrm{K}$, et al.: Navicula height, static versus dynamic. Poster presentation number 76 at I st l-Fab congress 2008.

29. Cornwall MW, McPoil TG: Relative movement of the navicular bone during normal walking. Foot Ankle Int 1999, 20:507-I2.

30. Reinking MF: Exercise-related leg pain in female collegiate athletes: the influence of intrinsic and extrinsic factors. $\mathrm{Am} \mathrm{J}$ Sports Med 2006, 34: I500-7.

31. Weiner-Ogilvie S, Rome K: The reliability of three techniques for measuring foot position. J Am Podiatr Med Assoc 1998, 88:38I-6.

32. Matsas A, Taylor N, McBurney $\mathrm{H}$ : Knee joint kinematics from familiarised treadmill walking can be generalised to overground walking in young unimpaired subjects. Gait Posture 2000, I I:46-53.

33. Jensen K, Juhl J: A new motion capture system for automated gait analysis based on multivideo sequence analysis. International Foot and Ankle Biomechanics (i-FAB) Ist Congress 2008:P60.

34. Bandholm T, Boysen L, Haugaard S, Zebis MK, Bencke J: Foot medial longitudinal-arch deformation during quiet standing and gait in subjects with medial tibial stress syndrome. J Foot Ankle Surg 2008, 47:89-95.

35. Areblad M, Nigg BM, Ekstrand J, Olsson KO, Ekstrom H: Threedimensional measurement of rearfoot motion during running. J Biomech 1990, 23:933-40.

36. Lai PP, Leung AK, Li AN, Zhang M: Three-dimensional gait analysis of obese adults. Clin Biomech 2008, 23(SuppI I):S2-S6.

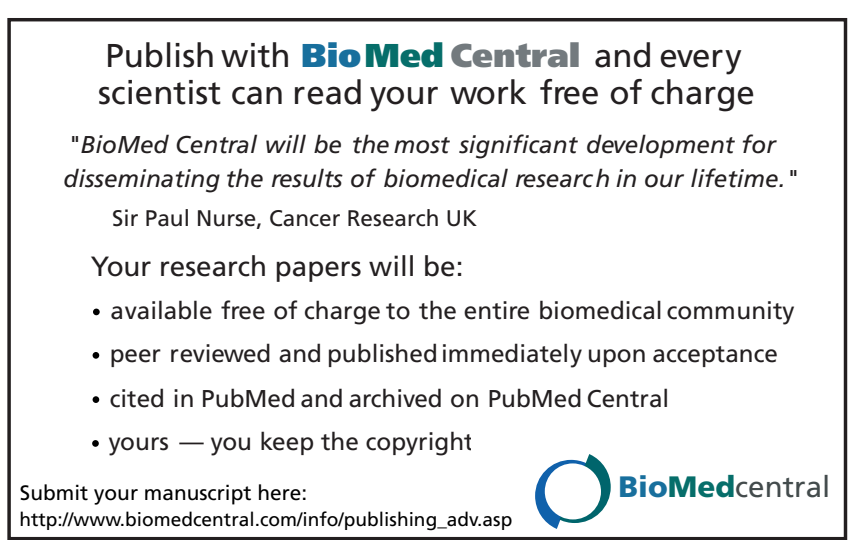

